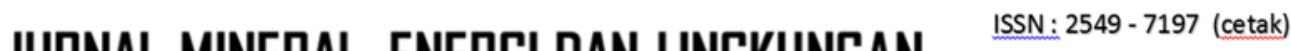

\author{
Vol. 3 No. 12019 p. 20 - 25
}

Available online at :

http://jurnal.upnyk.ac.id/index.php/JMEL

\section{Identifikasi Akuifer Air Tanah Dalam Menggununakan Metode Geolistrik Schlumberger di Desa Wedomartani, Kabupaten Sleman}

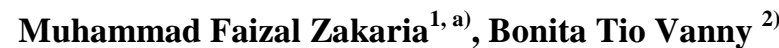 \\ 1) Universitas Pembangunan Nasional "Veteran" Yogyakarta \\ 2) Universitas Islam Negeri Sunan Kalijaga Yogyakarta \\ ${ }^{a)}$ mfaizal@upnyk.ac.id
}

\begin{abstract}
ABSTRAK
Air menjadi permasalahan utama dalam setiap daerah yang mengalami peningkatan penduduk yang cepat, salah satunya adalah desa Wedomartani, Kabupaten Sleman. Penelitian ini bertujuan untuk mengetahui cadangan air di desa Wedomartani serta mengetahui arah aliran air tanah di daerah tersebut. Penelitan dilakukan dengan melakukan survei geolistrik metode Schlumberger sebanyak 15 titik amat dengan bentangan rata-rata sepanjang $250 \mathrm{~m}$. Alat yang digunakan dalam pengukuran geolistrik adalah Resistivity Meter Syscal Jr. software yang digunakan dalam pengolahan adalah Progress 3.0. Hasil pengolahan data variasi resistivitas fungsi kedalaman per titik amat yang akan diinterpretasikan ke jenis batuan dan kandungan air. Resistivitas rata-rata akuifer air tanah pada desa Wedomartani adalah19,49 $\Omega \mathrm{m}$ dan kedalaman rata-rata akuifer air tanah pada desa Wedomartani sebesar $101 \mathrm{~m}$. Arah aliran air tanah dalam pada desa Wedomartani secara umum mengarah dari utara ke selatan dan barat (pada bagian selatan daerah penelitan)
\end{abstract}

Kata kunci: air tanah; geolistrik; resistivitas.

\section{ABSTRACT}

Water is the main problem in every region that has a rapid population increase, one of which is Wedomartani village, Sleman Regency. This study aims to determine the water reserves in Wedomartani village and find out the direction of groundwater flow in the area. The research carried out by measuring geolectricity method (Schlumberger configuration) survey of 15 very point acquisition with an average stretch of $250 \mathrm{~m}$. The tool used in geoelectric measurement is Resistivity Meter Syscal Jr. The software used in processing is Progress 3.0. The results of data processing is resistivity variations function of depth per point acquisition that will interpreted into rock types and water content. The average resistivity of groundwater aquifers in Wedomartani village is 19.49 Sm and the average depth of groundwater aquifers in Wedomartani village is $101 \mathrm{~m}$. The direction of deep groundwater flow in Wedomartani village generally leads from north to south and west (in the southern part of the research area)

Keywords: geoelectric; groundwater; resistivity.

\section{PENDAHULUAN}

Sumberdaya air tanah mempunyai peranan yang sangat penting sebagai salah satu alternatif sumber air baku untuk pasokan kebutuhan airbagi berbagai keperluan. Daerah kabupaten Sleman memiliki potensi sumber daya air alami yang cukup besar. Hal ini terlihat dengan keberadaan 154 sumber mata air, yang airnya mengalir ke sungai-sungai utama yaitu sungai Boyong, Kuning, Gendol, dan Krasak. Di samping itu terdapat anak-anak sungai yang mengalir ke arah selatan dan bermuara di Samudera Indonesia. Namun pemanfaatan sumber daya mata air alami atau air tanah ini akan cenderung terus meningkat dari waktu ke waktu,seiring dengan pertambahan jumlah penduduk. Berdasarkan data kependudukan dari Badan Kependudukan dan Pencatatan Sipil Kabupaten Sleman (Dinas Kependudukan dan Pencatatan Sipil Kabupaten Sleman - Dukcapil Kabupaten Sleman, 2019) kepadatan netto Kabupaten Sleman tahun 2015, tercatat laju pertumbuhan penduduk Kabupaten Sleman dari 5 tahun terakhir rata-rata sebesar 1,41\%. Jumlah kepala keluarga mengalami kenaikan sebanyak 66.233 KK (21,837\%) dari 303.201 KK pada tahun 2010 menjadi 369.534 KK pada tahun 2014. Rata-rata jumlah jiwa setiap rumah tangga sebanyak 2,88 jiwa per rumah tangga.

Desa Wedomartani merupakan salah satu desa yang berada pada kabupaten Sleman tepatnya pada kecamatan Ngemplak dapat dilihat pada Gambar 1. Desa Wedomartani pada akhir semester 2018 merupakan salah satu desa dengan jumlah penduduk terbanyak dalam satu desa (kelurahan) yaitu sebesar 28.041 jiwa. Antisipasi kebutuhan air baku, irigasi, dan kawasan industry di Desa Wedomartani dilakukan dengan pendataan potensi air, salah satunya adalah air tanah. Kegiatan pendataan potensi air tanah memerlukan metode eksplorasi bawah permukaan sehingga dapat mengetahui keberadaan air tanah di bawah permukaan. Salah satu metode geofisika yang dapat dipakai dalam eksplorasi air tanah adalah metode geolistrik Schlumberger (Gemilang, Kusumah \& Rahmawan, 2018; Hewaidy et al., 2015;Idehai \& Egai, 2014; Hadian 2019; Sehah \& Aziz, 2016) 


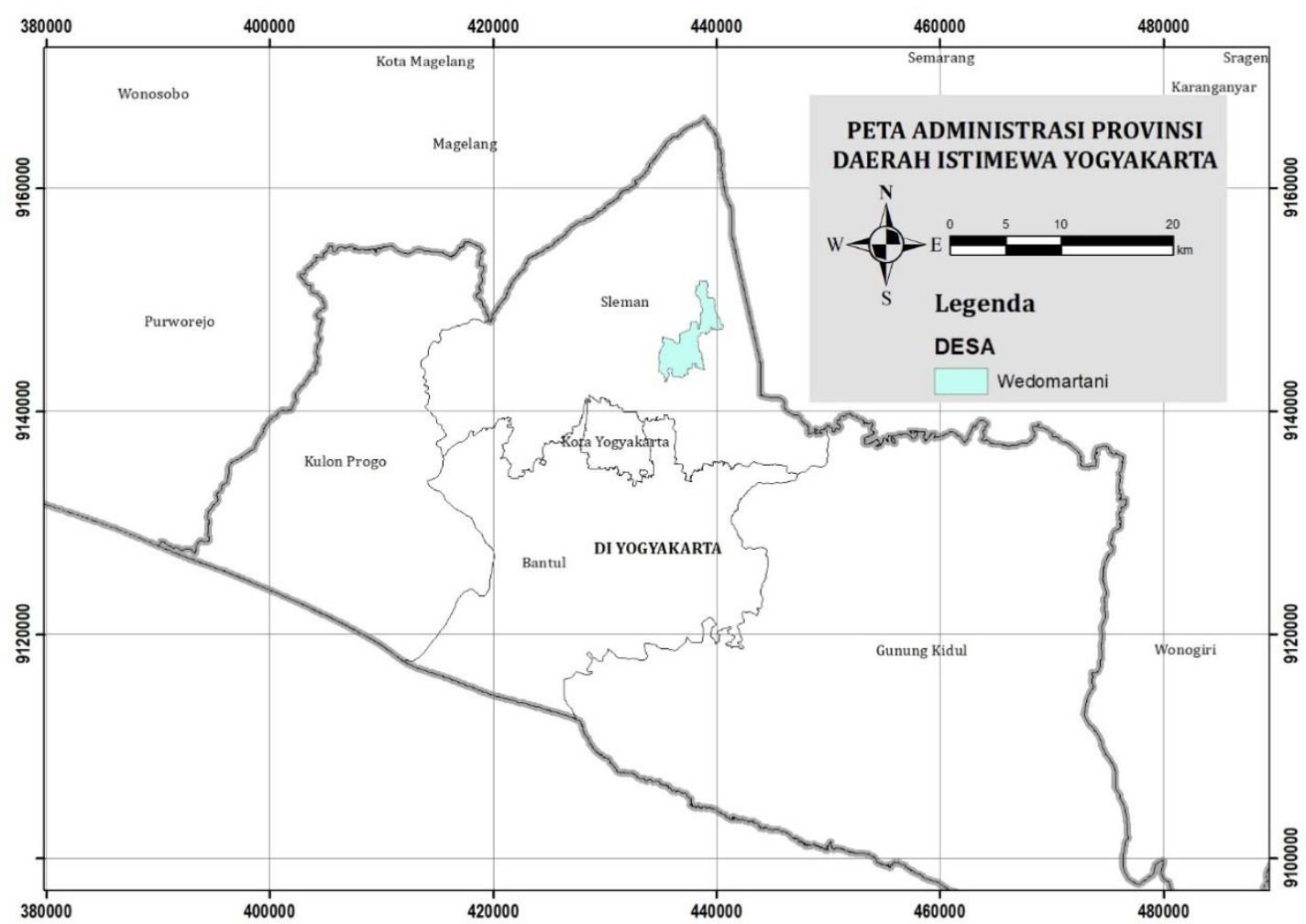

Gambar 1. Peta Administrasi Provinsi Daerah Istimewa Yogyakarta

Metode geolistrik merupakan salah satu metode dalam geofisika yang mempelajari sifat aliran listrik di dalam bumi dengan cara mengalirkan arus listrik DC (Direct Current) yang mempunyai tegangan tinggi ke dalam tanah (Szalai, Novak \& Szarka, 2009). Metode geolistrik ini juga merupakan metode yang cukup banyak digunakan dan hasilnya cukup baik (Jaka Yuwana, Pandjaitan \& Waspodo, 2017). Pendugaan geolistrik ini didasarkan pada kenyataan bahwa material yang berbeda akan mempunyai tahanan jenis yang berbeda apabila dialiri arus listrik. Air tanah mempunyai tahanan jenis yang lebih rendah daripada batuan mineral (Keller \& Frischknecht, 1966; Telford, Geldart \& Sheriff, 2010)

Penelitian ini bertujuan untuk mengetahui persebaran nilai resistivitas bawah permukaan di desa Wedomartani. Nilai resistivitas ini akan diinterpretasikan ke dalam jenis batuan dan kandungan air yang ada dibawah permukaan. Hasil akhir berupa persebaran kedalaman air tanah serta analisa mengenai arah aliran air tanah di desa Wedomartani.

\section{METODE}

Penelitian ini dilakukan dengan melakukan survei geolistrik Schlumberger (sounding) sebanyak 15 titik amat tersebar di satu desa, yaitu desa Wedomartani, Kecamatan Ngemplak, Kabupaten Sleman. Bentangan dari masing-masing titik amat adalah $300 \mathrm{~m}$ dan arah bentangan bervariasi tergantung dengan kondisi lapangan. Data yang didapatkan berupa data beda potensial $(\Delta \mathrm{V})$, arus $(\mathrm{I})$, dan hambatan $(\mathrm{R})$. Dari ketiga data tersebut dapat dihitung nilai resistivitas $(\rho)$. Resistivitas yang didapatkan dari lapangan merupakan resistivitas semu, sehingga perlu dilakukan pengolahan lanjut. Pengolahan dilakukan dengan melakukan inversi 1-D data resistivitas semu yang didapatkan dari lapangan sehingga didapatkan model bawah permukaan berupa model resistivitas sebenarnya pada tiap titip amat. Pengolahan menggunakan software Progress V3.0. Model resistivitas ini akan diinterpretasikan kedalam jenis batuan serta kandungan air tanah. Dari hasil 1D juga dibuat peta kedalaman air tanah dan peta elevasi air tanah dalam untuk mengetahui arah aliran dari air tanah dalam di daerah penelitian.

Lokasi titik pengukuran penelitian seperti yang dilihat pada Gambar 2 sebagian besar berada di daerah perkebunan, ladang dan persawahan warga. Dan sebagian lainnya berada di daerah pemukiman warga. Titik pengukuran bagian utara yakni titik B01, B03, B04 berada di bagian sisi persawahan warga dengan kondisi tanah yang gembur dan sedikit basah, sedangkan titik B02 berada didaerah perkebunan warga dengan kondisi tanah yang gembur. Untuk bagian tengah yakni titik B05, B09, B10 berada diantara perkebunan dan pemukiman warga sehingga kondisi tanahnyagembur dan sedikit bercampur bebatuan yang berada disisi jalan desa, sedangkan titik B06, B07, B08 dan B11 berada di bagian sisi persawahan yang kondisi tanahnya gembur dan sedikit basah. Kemudian titik bagian selatan yakni titik B12, B13, B1 
berada di daerah lading milik warga dengan kondisi tanah yang kering, sedangkan titik B14 masih berada dibagian sisi persawahan dengan kondisi tanah yang gembur dan sedikit basah.

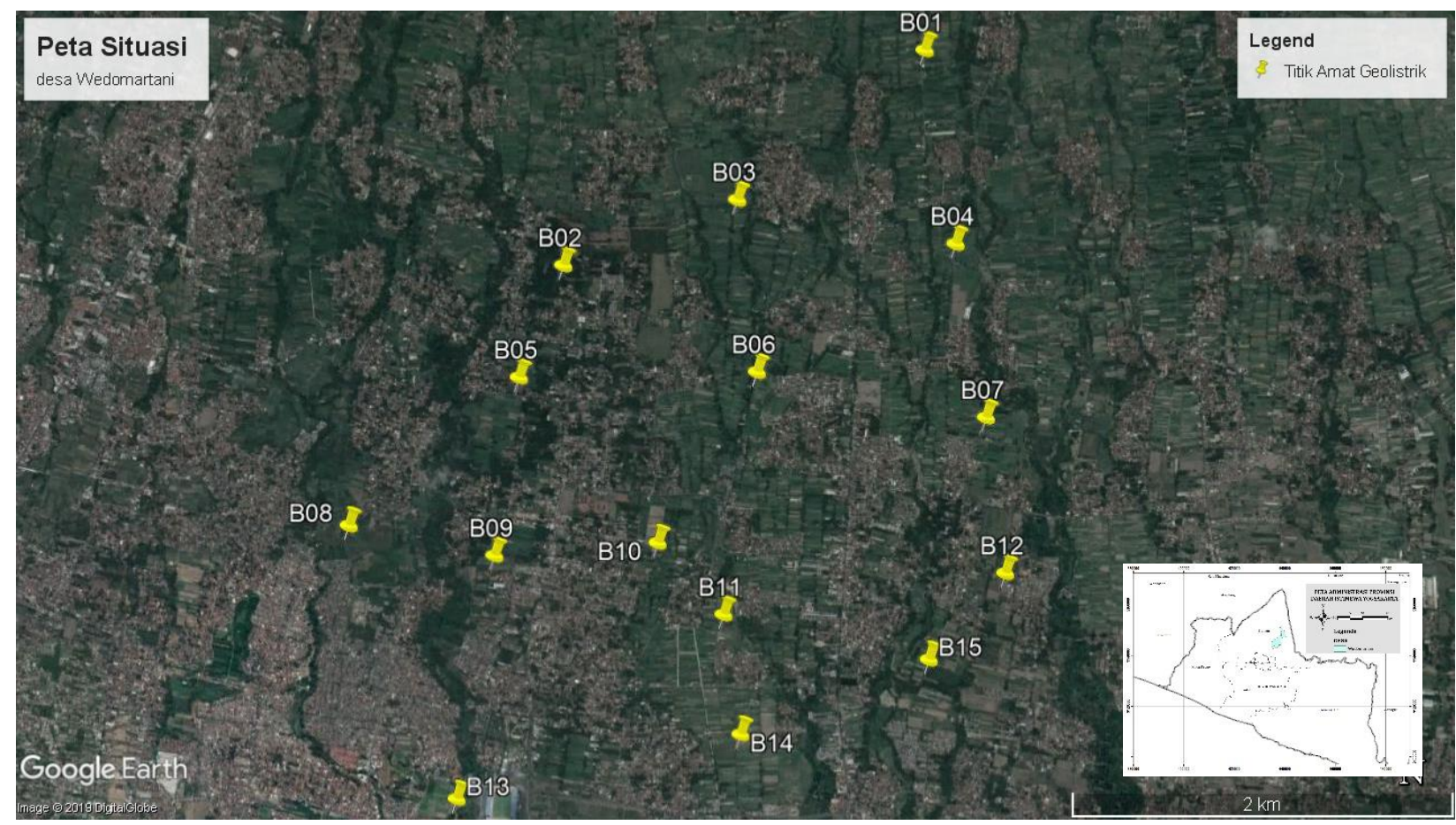

Gambar 2. Persebaran titik amat geolistrik di desa Wedomartani

\section{HASIL DAN DISKUSI}

Dari hasil pengolahan tiap titik sounding dilakukan analisis pengelompokan jenis lapisan batuan berdasarkan nilai resistivitas dengan memperhatikan kondisi geologi setempat yang kemudian dapat diketahui kedalaman dan ketebalan dari masing-masing lapisan batuan seperti pada gambar 3. Secara keseluruhan di area penelitian mempunyai nilai resistivitas yaitu :

- $\quad 67,7$ s.d $16724,7 \Omega \mathrm{m}$ (bervariasi dan kedalaman <10) : tanah penutup (top soil)

- $\quad 104,14$ s.d. $1039,82 \Omega \mathrm{m}$ (rata-rata : 206,30)

: breksi

- $\quad 11,6$ s.d $37,7 \Omega \mathrm{m}$ (rata-rata : 19,49)

: batu pasir (akuifer)

Akuifer diduga berada pada lapisan batuan penyusun berupa batu pasir. Batu pasir memiliki porositas yang cukup besar dan memiliki pelamparan yang baik di daerah Istimewa Yogyakarta (Rahardjo, 1995). Batu pasir yang mengandung air akan yang memiliki nilai resistivitas batuan rendah. Hal ini dikarenakan air merupakan konduktor yang baik sehingga akan menurunkan nilai resistivitas saat air berada pada suatu medium. Dari hasil interpretasi didapatkan satu lapisan yang diduga mengandung air tanah, dimana perlapisan tersebut merupakan akuifer dalam. Keberadaan akuifer tersebut melampar di semua titik pengukuran. Rata-rata kedalaman akuifer pada desa Wedomartani adalah 101 meter. Kedalaman paling dangkal berada pada titik B05 yaitu sekitar 81 meter dari permukaan. Interpretasi masing-masing titik amat dapat dilihat pada Tabel 1

Tabel 1. Tabel Interpretasi Tiap titik Geolistrik

\begin{tabular}{ccccc}
\hline No & $\begin{array}{c}\text { Nama } \\
\text { Titik }\end{array}$ & Kedalaman & Resistivity & Interpretasi \\
\hline \multirow{2}{*}{1} & b01 & 0 & 16724.92 & soil \\
& & 23.4 & 169.82 & breksi \\
& & 125.07 & 12.42 & air tanah \\
\hline
\end{tabular}




\begin{tabular}{|c|c|c|c|c|}
\hline \multirow[t]{3}{*}{2} & b02 & 0 & 1307.49 & soil \\
\hline & & 10.26 & 384.84 & breksi \\
\hline & & 108.25 & 25.34 & air tanah \\
\hline \multirow[t]{3}{*}{3} & b03 & 0 & 159.9 & soil \\
\hline & & 13.04 & 201.13 & breksi \\
\hline & & 112.36 & 20.36 & air tanah \\
\hline \multirow[t]{3}{*}{4} & b04 & 0 & 76.99 & soil \\
\hline & & 10.11 & 208.74 & breksi \\
\hline & & 86.18 & 37.6 & air tanah \\
\hline \multirow[t]{3}{*}{5} & b05 & 0 & 818.74 & soil \\
\hline & & 13.2 & 343.24 & breksi \\
\hline & & 80.74 & 25.51 & air tanah \\
\hline \multirow[t]{3}{*}{6} & b06 & 0 & 288.73 & soil \\
\hline & & 13.49 & 162.51 & breksi \\
\hline & & 97.02 & 19.54 & air tanah \\
\hline \multirow[t]{3}{*}{7} & b07 & 0 & 243.34 & soil \\
\hline & & 12.08 & 250.58 & breksi \\
\hline & & 120.55 & 23.27 & air tanah \\
\hline \multirow[t]{3}{*}{8} & b08 & 0 & 1717.95 & soil \\
\hline & & 11.23 & 253.12 & breksi \\
\hline & & 84.87 & 13.62 & air tanah \\
\hline \multirow[t]{3}{*}{9} & b09 & 0 & 175.99 & soil \\
\hline & & 18.02 & 122.75 & breksi \\
\hline & & 105.65 & 19.16 & air tanah \\
\hline \multirow[t]{3}{*}{10} & b10 & 0 & 457.22 & soil \\
\hline & & 17.1 & 82.86 & breksi \\
\hline & & 90.15 & 11.6 & air tanah \\
\hline \multirow[t]{3}{*}{11} & b11 & 0 & 299.99 & soil \\
\hline & & 10.76 & 228.09 & breksi \\
\hline & & 102.47 & 16.83 & air tanah \\
\hline \multirow[t]{3}{*}{12} & b12 & 0 & 1653.03 & soil \\
\hline & & 13.39 & 252.93 & breksi \\
\hline & & 110.09 & 22.5 & air tanah \\
\hline \multirow[t]{3}{*}{13} & b13 & 0 & 436.84 & soil \\
\hline & & 16.42 & 54.14 & breksi \\
\hline & & 115 & 18.3 & air tanah \\
\hline \multirow[t]{3}{*}{14} & b14 & 0 & 156.73 & soil \\
\hline & & 10.1 & 200.36 & breksi \\
\hline & & 85.45 & 12.32 & air tanah \\
\hline \multirow[t]{3}{*}{15} & b15 & 0 & 496.04 & soil \\
\hline & & 15.96 & 74.02 & breksi \\
\hline & & 86.84 & 14.06 & air tanah \\
\hline
\end{tabular}


Untuk mengetahui arah aliran dari air tanah dalam tersebut, digunakan data posisi ketinggian akuifer dengan cara mengurangkan nilai elevasi titik amat dengan kedalaman akuifer. Persebaran ketinggian akuifer dapat digunakan untuk mengetahui arah aliran air pada akuifer dalam. Peta ketinggian akuifer dan arah aliran air ditunjukkan pada Gambar $\mathbf{5}$. Arah aliran air pada akuifer dalam di daerah penelitan secara umum mengarah ke selatan. Tetapi, pada bagian selatan daerah penelitian, arah aliran cenderung berbelok ke arah barat yang dikarenakan terdapat suatu tinggian lapisan pada bagian barat.

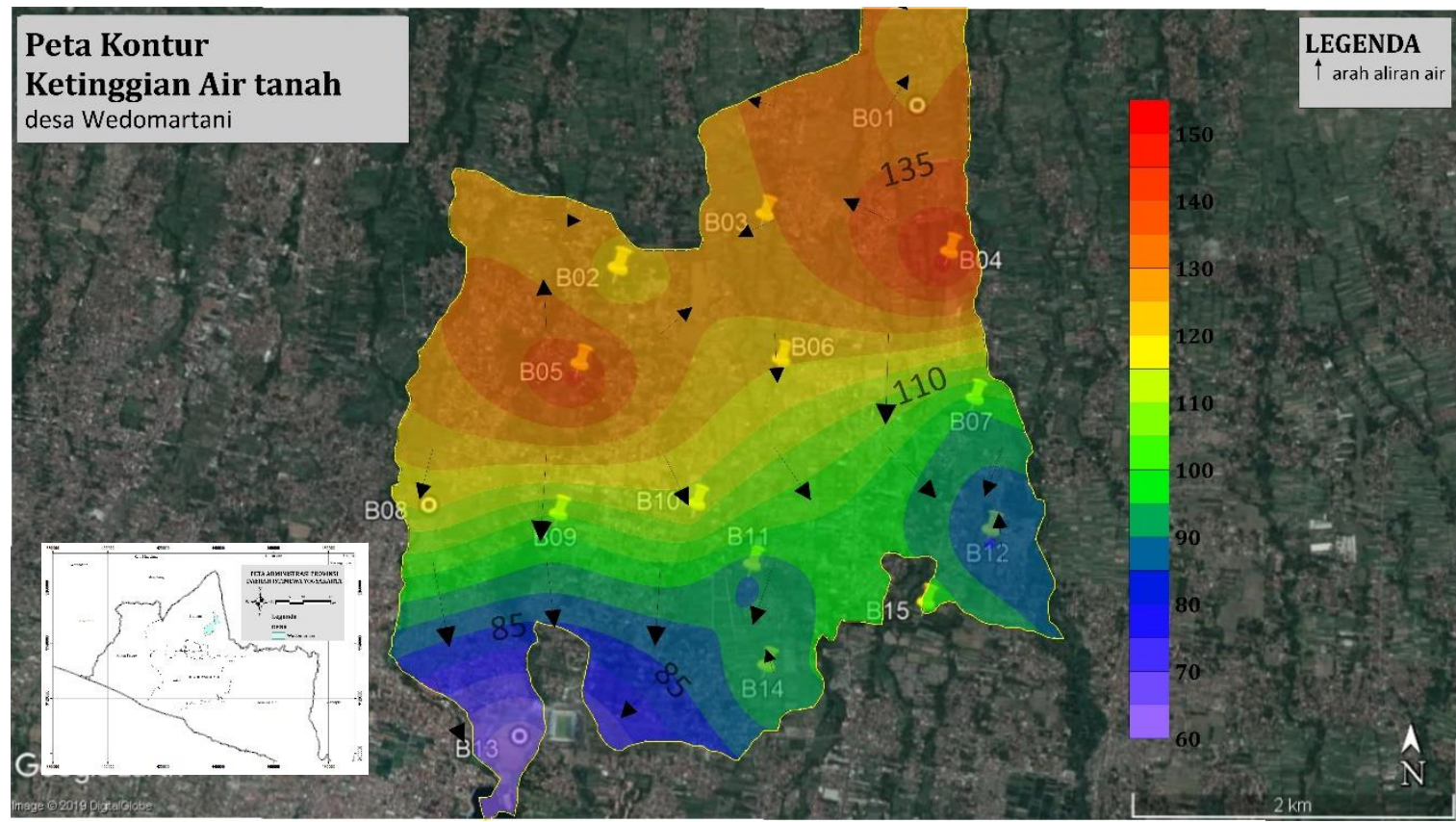

Gambar 5. Peta Kontur Ketinggian Air Tanah desa Wedomartani

\section{KESIMPULAN}

Kesimpulan yang didapatkan dari penelitan ini berupa varias nilai resistivitas bawah permukaan. Resistivitas batu pasir (akuifer) yang mengandung air bernilai $19.49 \Omega \mathrm{m}$ dan lapisan tersebut berada pada kedalaman yang bervariasi dengan kedalaman rata-rata $101 \mathrm{~m}$. aliran air pada akuifer secara umum mengarah ke selatan dan barat (pada bagian selatan)

\section{UCAPAN TERIMAKASIH}

Terimakasih penulis ucapkan kepada seluruh mahasiswa geofisika UIN Sunan Kalijaga angkatan 2011 yang ikut melakukan pengambilan data, terutama Bonita Tio Vanny yang menjadi koordinator pengambilan data penelitian ini.

\section{DAFTAR PUSTAKA}

Dinas Kependudukan dan Pencatatan Sipil Kabupaten Sleman - Dukcapil Kabupaten Sleman. (2019). Retrieved from https://dukcapil.slemankab.go.id

Gemilang, W., Kusumah, G. and Rahmawan, G. (2018). Potensi air tanah di bagian beach ridge Daerah Labuan Bajau dan sekitarnya Kabupaten Simeuleu berdasarkan analisis pengukuran geolistrik. Jurnal Geosaintek, 4(1), p.7.

Hadian, M. (2019). Sebaran akuifer dan pola aliran air tanah di Kecamatan Batuceper dan Kecamatan Benda Kota Tangerang, Propinsi Banten.

Hewaidy, A., El-Motaal, E., Sultan, S., Ramdan, T., El khafif, A. and Soliman, S. (2015). Groundwater exploration using resistivity and magnetic data at the northwestern part of the Gulf of Suez, Egypt. Egyptian Journal of Petroleum, 24(3), pp.255-263.

Idehai, I., \& Egai, A. (2014). Aspects of Geophysical Exploration for Groundwater Using Vertical Electrical Sounding (VES) in Parts of University of Benin, Benin City, Edo State. Journal Of Applied Sciences And Environmental Management, 18(1), 19. doi: 10.4314/jasem.v18i1.3 
24 ISSN 2549-7197 (cetak), ISSN 2549-564X (online)

JMEL, Volume 3 Nomor 1, 2019

Jaka Yuwana, N., Pandjaitan, N., \& Waspodo, R. (2017). Prediksi cadangan air tanah berdasarkan hasil pendugaan geolistrik di Kabupaten Grobogan, Jawa Tengah. Jurnal sumber air 13(1), 23. doi: 10.31028/jsda.v13.i1.23-36 
Keller, G., \& Frischknecht, F. (1966). Electrical methods in geophysical prospecting. Oxford: Pergamon Press.

Rahardjo, W., Sukandarrumidi, Roside, H.M.D. (1995). Peta Geologi Lembar Yogyakarta, Jawa. Pusat Penelitian dan Pengembangan Geologi

Sehah, S., \& Aziz, A. (2016). Pendugaan kedalaman air tanah menggunakan metode geolistrik Konfigurasi Schlumberger di Desa Bojongsari, Kecamatan Alian, Kabupaten Kebumen. Jurnal Neutrino, 8(2. APRIL), 41. doi: $10.18860 /$ neu.v8i2.3239

Szalai, S., Novak, A., \& Szarka, L. (2009). Depth of Investigation and Vertical Resolution of Surface Geoelectric Arrays. Journal Of Environmental \& Engineering Geophysics, 14(1), 15-23. doi: 10.2113/jeeg14.1.15

Telford, W., Geldart, L., \& Sheriff, R. (2010). Applied geophysics. Cambridge: Cambridge Univ. Press. 